\title{
BIOCHEMICAL BASIS OF ANTIIFLAMMATORY PROPERTIES OF PEPTIDE COMPLEX OBTAINED FROM THE COD LIVER (GADIDAE)
}

\author{
(C) Kryshen K. L. ${ }^{2}$, Demchenko D. V. ${ }^{1}$, Ribakova A. V. ${ }^{1}$, Rydlovskaya A. V. ${ }^{1}$, \\ Atsapkina A. A. ${ }^{1}$, Beketova D. V. ${ }^{1}$, Pozharitskaya O. N. ${ }^{1}$, \\ Makarova M. N. ${ }^{1}$, Dadali V. A. ${ }^{2}$, Makarov V. G. ${ }^{1}$
}

${ }^{1}$ St-Petersburg Institute of Pharmacy, Russia

${ }^{2}$ North-West State Medical University named after I. I. Mechnikov, Saint-Petersburg, Russia

Drugs designed to act against individual molecular targets cannot usually combat diseases that affect multiple tissues or cell types such as immunoinflammatory disorders. Combination drugs that impact multiple targets simultaneously are better at controlling complex disease systems, are less prone to drug resistance and the standard of care in many important therapeutic areas. The aim of the study was to evaluate the therapeutical anti-inflammatory potential and molecular mechanisms of newly designed multipeptide complex (PC) obtained from the cod liver (Gadidae). PC is a standardized extract that contains peptides, phospholipids, free amino acids and trace elements. It was shown that $0,01 \%$ injection solution in doses 2,4 and $8 \mathrm{mg} / \mathrm{kg}$ have high anti-inflammatory effects evaluated on the models of carrageenan air pouch in the rat and contact dermatitis in mice. Inflammation is a complex pathological process associated with exaggerated human immune system involving various activated immune cells and bio-molecules. Within several inflammation cascades or pathways there are often pivotal molecular targets that, when antagonized or neutralized, block the output of the pathway. Historically, at least over the past 20 years in the modern era of target-based drug discovery, a relatively small number of pivotal targets have been identified that have yielded any successful anti-inflammatory drugs. Most of these are antagonists of endogenous proinflammatory mediators such as prostaglandins, leukotrienes and histamine. These targets include the $\mathrm{H} 1$ receptor for histamine, the enzymes cyclooxygenase 1 and 2 (COX-1 and COX-2), the cytokine tumor necrosis factor- $\alpha$ (TNF- $\alpha$ ) and the receptor for the cysteinyl leukotrienes $\mathrm{C} 4$ and D4. It was shown in vitro that substance of PC are the selective inhibitor of COX2 (IC50 $=5-10 \mu \mathrm{g} / \mathrm{ml}$ ) and 5-LOX (IC50 = 10,2 $\mu \mathrm{g} / \mathrm{ml})$. Also PC in concentrations 1, 2, 4 and $16 \mu \mathrm{g} / \mathrm{ml}$ decreased 2-fold the histamine release from the rat basophils cell line RBL1 induced by the compound 48/80. Ex vivo studies of PC action on $\mathrm{H} 1$-histamine receptors in guinea pig ileum showed that the PC inhibited smooth muscle responses to histamine. The substance was effective in all studied concentrations $10,20,100$ and $1000 \mu \mathrm{g} / \mathrm{ml}$, but the most pronounced effects were observed at a concentration of $1000 \mu \mathrm{g} / \mathrm{ml}$. Perfusion with PC decreased the amplitude of histamine-induced smooth muscle response of up to $95 \%$ from control (potassium cloride). The time of the maximal response to histamine was increased in 45-fold compared to control. The so-called «one drug one target» drugs have revolutionized modern medicine and, in many cases, can be considered wonder drugs. Unfortunately, many patients are unable to benefit from these therapies because of pharmacogenomic effects. For example, some patients could have differences in key diseaserelevant biological pathways compared with the majority of the population, and this could alter the contribution of a particular target to the disease in these individuals. In such cases, the action of an alternative target might predominate and these patients could benefit from a combination that simultaneously impacts the principal and alternative targets. Based on the information obtained from our study, we can conclude that tested PC is a multitarget anti-inflammatory drug. It was shown that $\mathrm{PC}$ is a selective inhibitor of COX2 and 5-LOX, inhibitor of $\mathrm{H} 1$-histamine receptors and have the ability to decrease the histamine release from basofils and mast cells. 